\title{
A Case Study on Online Mathematics Teaching with Pen-based Technology: Experiences of Two Instructors
}

\author{
Hasan Karal \\ Karadeniz Technical University, Turkey \\ Mehmet Kokoc \\ Karadeniz Technical University, Turkey \\ Canan Colak \\ Anadolu University, Turkey \\ Yasin Yalcin \\ Florida State University, United States
}

\begin{abstract}
The purpose of this study was to explore instructors' perspectives on the effect of using pen-based technology in the online mathematics courses and understand instructors' experiences in online mathematics teaching with pen-based technology. In this study, two instructors who taught online mathematics courses in fourteen weeks used digital pen as a pen-based technology. The data were obtained from semi-structured interviews and observation of online mathematics course records. The findings indicated that the use of digital pen in the online mathematics course was fairly beneficial in pedagogical and interaction aspects and it was necessary to use digital pen in online mathematics courses for displaying steps of problem solving process synchronously. It was concluded from the study that digital pen technology plays a positive role in the enhancement of interaction between the elements of an online learning environment by providing real-time feedback to students and permitting to digitize mathematical concepts. The observation findings also supported the statements of the instructors. The findings of the study have further provided some insight into how to use digital pen by an instructor in online mathematics course efficiently.
\end{abstract}

Keywords: Online mathematics course; Digital pen, Digital ink technology; Interaction in online learning; Teaching with digital ink

\section{Introduction}

Educational systems have been affected greatly by global technological changes and the resulting reform initiatives (Morewood, Ankrum, \& Bean, 2010). As a consequence, technology has become more common in learning environments (Roblyer, 2006). Together with changing needs and living conditions, attempts to seek solutions to the problems in education highlight online distance education as an alternative to the existing practices (Schunk, 2008).

Online learning has become an important educational model in the globalizing world of today. It provides learners with the opportunity to receive education at a lower cost and offers a 
more effective learning environment independent of time and space. Due to the opportunities and flexibility it provides for individuals and societies, online distance learning has become a globally-preferred option (Newby et al., 2006). Despite having many advantages, problems which encountered particularly in the teaching of applied courses such as lack of motivation, no direct contact with the teacher, and possibly low interaction in the learning environment, stand out as the three important limitations of distance education (Moreno-Ger et al., 2008; Watson, 2010). Such limitations underline the importance of "interaction" in online learning. From this perspective, it is thought that a high level of interaction between learner and teacher in an online learning environment is a necessity for improving the quality of online applied/practical courses (such as Math and Physics).

The importance of interaction in online distance learning has been frequently emphasized in the literature (Anderson, 2003; Beaudoin, 2002; Watson, 2010). Interaction plays a key role in achieving high quality in online distance learning and in realizing a successful learning process (Dzakira \& Idrus, 2003; Nehme, 2008). Especially, learner-teacher interaction is important for the experience, satisfaction and motivation of the learner; academic achievement; education quality; and the overall success of online distance learning (Dzakira \& Idrus, 2003; Liao, 2006; Offir, Lev \& Bezalel, 2008). Learner-teacher interaction can be achieved in the DE environment by ensuring the active participation of the students throughout the learning process. This type of interaction contributes both to the increased success of learning and to prevent the isolation of students from learning environment (Nehme, 2008). Interaction between students and teachers is necessary to prevent open and distance learners from feeling isolated. In addition, student feedback is an important factor in student-teacher interaction (Berge, 2002). Feedback is very important in online learning environments where applied courses (based on numerical problems requiring process steps) are taught (Thurmond \& Wambach, 2004). Failure to provide instant and sufficient feedback to online distance learners gives rise to problems such as difficulties in self-evaluation in the learning processes and prevention of successful completion of the learning process (Jin, 2005).

Online distance learning enables a higher level of interaction compared to asynchronous distance learning. The growing use of the Internet for online distance learning facilitates interaction (Watson, 2010). Interaction and feedback in online distance learning is ensured via human-computer interaction tools, PowerPoint, forums, blogs, podcasts, on-line discussion groups and media, live chat, live visual communication and written chat tools (Beldarrain, 2006; Collis, De Boer, \& Slotman, 2001; Jung et al., 2002). These technological tools cannot be sufficient to ensure interaction and an effective learning process in the online teaching of mathematics (MacLaren, 2014). For this reason, various emerging technologies, as well as penbased technology, have begun to be used in recent years to facilitate interaction and feedback, particularly in applied online distance courses (Mehlhorn et al., 2011).

Pen-based technologies allow teachers to take notes on paper in their own handwriting; these notes are then digitized and stored on digital media. Pen-based technologies (such as Tablet PCs, digital ink technologies, and digital pens) can also be used like a computer mouse, and the pictures drawn can be digitized. Digital ink technologies that provide mobility to users are similar to the interaction between paper and pencil (Alvarez, Brown, \& Nussbaum, 2011). There are also pen-based technologies which enable synchronous handwriting and visual recording. Taking into consideration the features of digital pen, this technology may enable students to see notes taken by teachers in their own handwriting through digital media, as well as to receive real time feedback in an online learning environment. 
In online mathematics courses, the display of the mathematical concepts, problems and process steps of the solutions and effective realization of the student-teacher interaction are two factors that affect learning outcomes (Karal et al., 2013). In learning about ways of mathematical thinking, logical inference and discussion of alternative solutions via studentteacher interaction constitute the basic principles of mathematics education (Baki, 2006). In addition, writing is a must for doing mathematics (Artemeva \& Fox, 2011). Radford (2008) emphasized that mathematical thinking occurs through a sophisticated semiotic coordination of speech, body, gestures, symbols, and tools. In online distance learning, students and teachers are integrated into the system via a computer; the computer screen is used for reading and the keyboard for writing (Bernhardt et al., 2004). It is difficult to achieve sufficient interaction in an online learning environment by displaying mathematical concepts and symbols, which play a significant role in mathematics education, solely through use of a keyboard. This seems to be a limitation in the process of learning mathematics by online learners. Prior research reveals that mathematics instructors can have difficulty when explaining mathematical concepts visually in blended and online distance mathematics course (Glass \& Sue, 2008; Karal et al., 2013). This situation brings to mind that the pen-based technologies which digitize and computerize handwritten notes through the use of pen-based technologies as digital ink or digital handwriting. Pen-based technologies may have potential to solve many issues in online mathematics course (Karal et al., 2013). By using pen-based technology, online mathematics teachers can write digitally, save notes easily for archiving, and transfer the notes to the digital screen by software. When online teacher handwrites on any printed paper with digital pen, online students can see the handwriting synchronously in online learning environment. Therefore, studies need to be conducted on whether the limitations of online mathematics courses (such as interaction, feedback and symbol display limitations) can be eliminated via digital pen-based technologies.

The literature review revealed a limited number of studies on the use of digital ink technology in distance education. Related studies show that hardware and software are used to support digital pen-based technologies together (Hofacker \& Ernie, 2009; Karal et al., 2013; Reins, 2007; Siozos et al., 2009; Wang, Gould, \& Fulton, 2007; Varadarajan et al., 2008). The study by Wang, Gould and Fulton (2007) examined student and teacher opinions about the role of digital ink technology and DyKnow software in the interactive classrooms of distance education. This software enables the display from a whiteboard to be transferred to the computer screens of the students; this display can be controlled by both the students and the teacher. The results showed that the participant teachers and students were satisfied with the DyKnow software and desktop computers they used. In general, the students commented that new technological tools individualized their learning and turned it into an exciting and interactive process. Karal et al. (2013) evaluated mathematics course offered through online distance education based on online students' perspectives. The findings indicated that use of digital pen during online mathematics course and giving immediate feedback through digital pen increased the interaction between the instructor and online students.

In their analysis of the effects of the use of digital ink technology in the learning environment, Reins (2007) concluded that the digital pen technology used in the mathematics course had a positive impact on the learning process. However, this study did not focus on the effects of digital pen technology on the pedagogical approaches adopted by the teachers and interaction among instructor, students, and online learning environment. Varadarajan et al. (2008) investigated the effects of digital ink technologies (such as PDA and tablet computers) on the active learning experiences of students. Within the scope of this study, the researchers developed a DigiNoteOR (Digital Notes Organizer and Retrieval) system which enables the 
recording, organization and retrieval of personal notes taken by students during instruction and while studying. Varadarajan et al. (2008) concluded that the mean success score of the students who used the DigiNoteOR system was higher than those who used traditional textbooks while studying. In another study, Siozos et al. (2009) focused on the key challenges faced by computer-based assessment in secondary education. They designed an application called "MyTest" which enables use of digital ink capabilities and Tablet Pc. The results of the study showed that when MyTest application was conducted with using Tablet Pc, as compared to using traditional PC, it was be more efficient, flexible, convenient and useful.

The studies relevant to digital ink or digital pen technologies in education show that using digital technological tools contribute to students and instructors in face-to-face and blended mathematics courses. However, there is limited research focusing on experiences of online mathematics instructors and how using digital pen-based technology affect online teaching process of mathematics and overcome the problems in online mathematics course. Therefore, this study focuses on the question of how using pen-based technology can support online mathematics teaching and contribute to online mathematics instructor.

\section{Purpose of the Study}

The use of digital technologies in mathematics instruction can change the teaching processes of related courses (Heddens \& Speer, 1997). This raises the question of how the use of digital technologies as digital pen in online learning environments can affect the flow of the teaching process. Temizoz and Ozgun-Koca (2008) underlined the necessity of not ignoring the importance and effect of the instructional approach adopted by instructors in their teaching applications. Instructors adopt a pedagogical approach along with specific teaching methods and techniques in face-to-face learning environments. Therefore, consideration should be given to whether it is possible for instructors to have the same facilities and flexibility in the online distance learning environment. However, it should not be directly concluded that an instructor who is successful in a traditional classroom environment will be successful in the online distance learning environment (Moore, 1997). Therefore, changes in the pedagogical approach of an online instructor teaching his/her course using digital pen-based technology in an online distance learning environment should also be studied.

The main purpose of this study was to explore instructors' perspectives on the effect of using digital pen in online mathematics courses and understand instructors' experiences in online mathematics teaching with digital pen. The research questions are as follows:

- What are instructors' perspectives regarding the effect of using digital pen in online mathematics courses?"

- What are the experiences of instructors in online mathematics teaching with digital pen technology?

\section{Method}

This research is based on a qualitative case study enabling researchers to focus on a case dependent upon a specific problem (McMillan, 2000; Wellington, 2000) and to obtain in-depth information (Patton, 2002). The qualitative case study is used in many situations to contribute to our knowledge of a focused phenomenon within a real-life context (Yin, 2009). In this study, 
experiences of two faculty members in process of study were analyzed individually as units of analysis being the cases (Patton, 2002).

\section{Participants}

A purposeful sampling method was used in the selection of the participants for the study (Patton, 2002). The researchers selected the participants in line with the requirements of the research problem (Morse, 1991). Two faculty members as experts in the field of mathematics teaching were selected for the study. Both participants were male. Why these two faculty members qualified as participants for this case study was that they have taught an online mathematics course by using digital ink technology actively. According to ethical principles, the real names of the participants are not used; the participants were referred to as K1 and K2. K1 is an assistant professor in a vocational associate degree program in the department of "Computer Programming" and, K2 is an associate professor in undergraduate program in the department of "Mathematics Education" at a state university in Turkey. Both participants did not have any distance education experience prior to the semester in which the study was conducted.

\section{Context of the Study}

This case study was conducted in the context of vocational associate degree program and a teacher education program at a state university in Turkey. In the study procedure, K1 and K2 taught an online mathematics course, separately. 82 associate degree students participated in the course of $K 1$ and 47 undergraduate students participated in the course of K2. There were no students' experiences regarding the use of pen-based technology before. Each participant taught a mathematics course for a total of 48 hours for one semester. Both courses were taken a total of 12 weeks during a semester. Four hours of courses were conducted per week. The participants conducted their courses through online learning environment supported by Adobe Connect as web conferencing system. The online environment enabled visual, audio and written communication and file-sharing between the instructor and the learners. Digital pen used by the participants records handwriting with the help of a receiver placed above the paper and instantly digitizes the written text. This pen can also be used as a computer mouse whenever desired. The participants only used the digital pen technology during conducting the online mathematics courses. The students attended the courses did not use digital pen in the study process due to not having other digital pen.

\section{Data Collection Tools}

Interview and observation techniques were used together in the data collection process of the study. Semi-structured interview was chosen because it enables the interviewees to express themselves and provide detailed information about the research problem (Johnson \& Christensen, 2004; Yin, 2009). The interview form used in the study was developed by the researchers. It is generally suggested that open-ended questions should be included in qualitative interviews (Johnson \& Christensen, 2004). The researchers developed open-ended and easy-to-understand questions in order to avoid leading the participants and to arranging the questions in a logical manner while preparing the interview form. Three experts were asked to provide feedback about validity of the interview form. All interviews were carried out 
individually in official faculty office in the scheduled time after semester. Each interview lasted approximately 34 minutes and recorded with a video recorder with the informed consent of the participants. Some questions were posed in different ways, depending on the mood of the participant at the time of the interview and the interview conditions. Questions were classified into groups according to the research problem. The questions included in the interview form and their related sub-problems are attached in the Appendix.

The researchers used the unstructured observation technique. To this end, the records of the online mathematics courses taught for 14 weeks by the instructors were observed by the researchers. The data obtained at the end of the observation of the course records were used to interpret the interview data.

\section{Data Analysis}

The data were analyzed through content analysis method (Patton, 2002). The content analysis defined the relationship between the collected data, conceptual codes, and sub-themes in order to analyze the study data. First, the raw data obtained via the semi-structured interviews were read twice by the researchers to prevent possible biases. The data were cross-checked through member check (Lincoln \& Guba, 1985). After the member check, first-level coding was performed and the data were reduced. Tables were drawn while defining themes. After the inter-rater reliability analysis, the codes and themes were rearranged according to study subdimensions. Direct citations were taken from the participant statements for data display. Then the data were interpreted and the results of the study emerged. The codes assigned by the researchers were used instead of the real names of the participants. Steps in the data analysis of the study are shown in Figure 1.

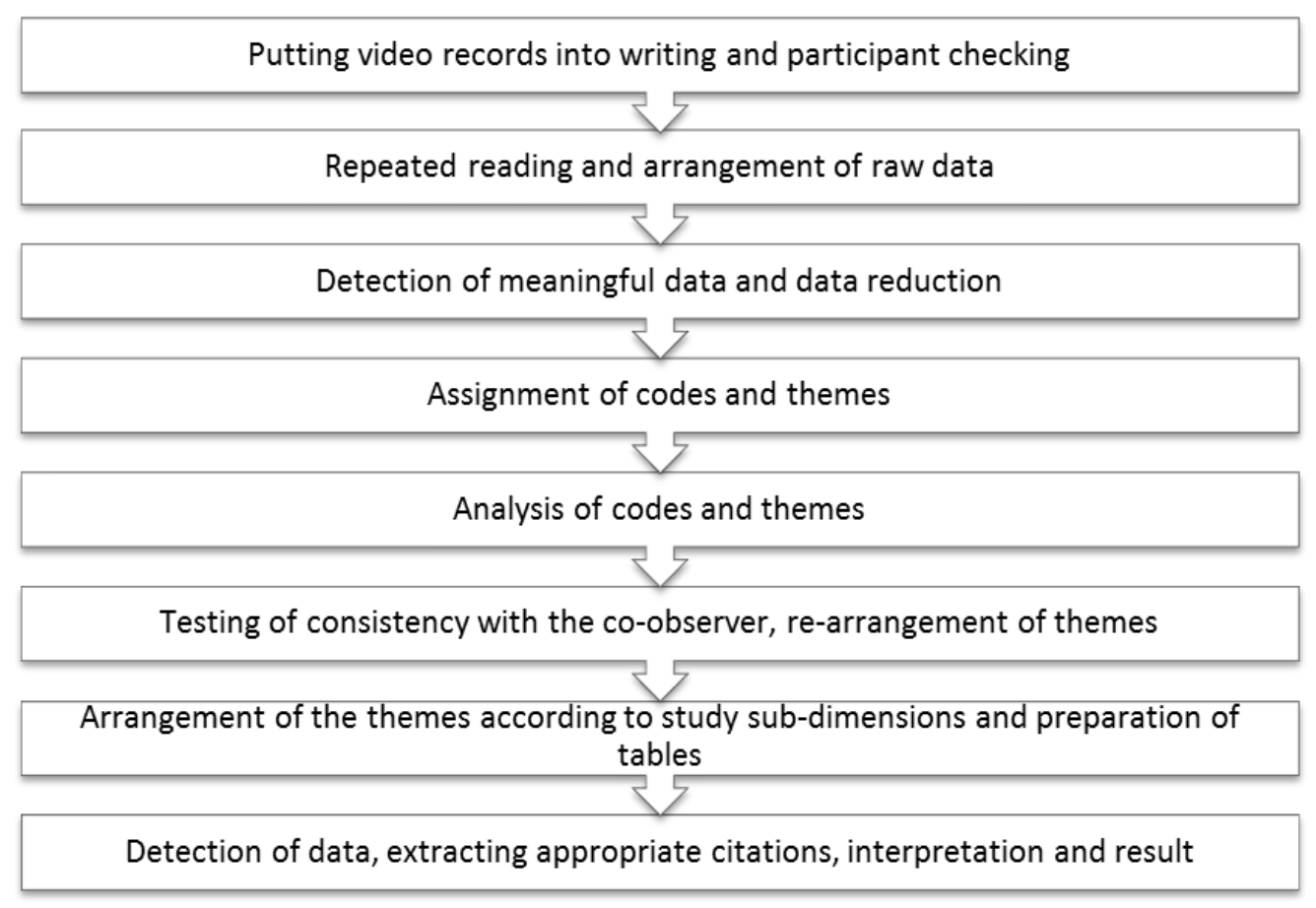

Figure 1. Data Analysis Steps 


\section{Validity and Reliability of the Study}

Qualitative terms such as credibility, transferability, dependability, and confirmability replace the quantitative terminology as positivist criteria of internal and external validity, reliability, and objectivity (Denzin \& Lincoln, 2000). Member check, data triangulation, and investigator triangulation were carried out for credibility and trustworthiness of the study (Lincoln \& Guba, 1985). The interview transcripts and draft research report were checked by the participants (member check) to ensure the cross-check of the study. Direct citations were taken from the interview data. The method and context of the study were described in detail to ensure transferability of the study. Without any interpretation and remaining faithful to the nature of the qualitative data, direct citations were provided the interviews data re-arranged based on emerging themes to the readers (Yildirim \& Simsek, 2008).

In this study, the researchers asked the questions with a similar approach and recorded the interviews. In addition, data triangulation was performed to ensure data consistency, and data were collected by using both observation and interview methods (Sowell, 2001). To ensure confirmability of the study; data collection tools, interviews' raw data, the code schemes and analysis notes were kept for audit trail (Lincoln \& Guba, 1985).

\section{The Role of the Researchers}

The researchers paid attention to ensuring that their bias and hypothesis did not overshadow the impartiality of the study data or affect the analysis process. The researchers tried to address the cases and phenomena with an integrated and multi-dimensional approach and to use their sympathetic skills in the data collection process. During the interviews, the researchers paid special attention to impartiality and acted carefully to prevent their body language from negatively affecting the participants. It was recorded that participants did not feel uncomfortable and did not tend to use short expressions and closed attitudes during the interviews, and that researchers' personal behaviors did not impact the natural environment. Subjectivity and personal opinions of the researchers were determinant in the interpretation process of the analyzed data. Although one of the researchers was known by participants, this situation did not cause negative effect on context of the study. The researcher was an expert in distance education who often gave technical support to participants as a formal work process during online mathematics course whenever the participants ask for help. Thus, behaviors of the participants did not change according to the researchers' presence.

During the present study the researchers gained the trust of the participants by revealing their own identities and the aim of the study. The confidentiality principle described by Miles \& Huberman (1994) was followed, and the data obtained were put in writing and sent to the participants as raw data to be reviewed (McMillan \& Schumacher, 2010). The participants were guaranteed that their names or identities would not be used for any purpose other than study data.

\section{Findings}

The findings were obtained through analysis of the data collected through semi-structured interviews and unstructured observations. Participants were asked 14 questions during the interviews. Three of these questions were about their awareness of digital pen and the 
problems encountered during use; five of them were about the effects of the use of digital pen on the pedagogical approach of the instructors (teaching method, classroom management, time management etc.); three were about instructor-student interaction; and two were about the advantages this technology offers to the instructors.

The researchers analyzed the data separately. Then these separate analyses were compared and the themes were grouped according to common features. The six themes that emerged at the end of the data analysis were as follows:

\section{Awareness of Digital Pen, Problems Encountered During the Use and the Assistance Received in This Context}

When the participant instructors were asked about their awareness of digital pen prior to teaching in an online learning environment; K1 commented: "I read something about the digital pen in the computer or technology journals. I only knew about the technology but had no idea about how to use it or its features." [K1]. K2, on the other hand, commented; "Before teaching distance education courses, I was unaware of the digital pen. I learned about it during this process."

Taking into consideration the fact that both instructors were using this technology for the first time, they were asked about the problems they encountered and assistance they received when using this technology. K1 stated that he had problems which arose when using the system for the first time and gave the reasons as follows:

"... if you use a system for the first time, there are some problems related to the first use. The most common problem I have experienced is that the pen turned into mouse mode several times and, honestly, I still do not know how I turn on/off mouse mode."[K1]

"I have to share something with you: We never read the user manual of any device we buy. There are only a few people who read such manuals. This habit applies to any kind of device. Of course, there are many reasons for doing so. I have not read the user manual of this device." [K1]

The second most common problems encountered by K1 are; (a) the position of the receiver changed when he was replacing the paper on which he wrote with digital pen, so he had to relocate the receiver again, which took some time, (b) he had difficulty in writing words straight; and (c) some parts of the text could not be viewed by the students when he wrote the words quickly. In K1's words, "When I write fast, I see that the writing is very bad or interrupted."

The problems experienced by $\mathrm{K} 2$ in the use ofdigital pen are (a) the paper slipped when writing, therefore, the writing displayed on the computer screen was bad; (b) the pen had a short user life; (c) the pen turned into mouse mode by accident; and (d) some letters were not displayed on the computer screen when writing rapidly. $\mathrm{K} 2$ describes these problems as:

"The device controls the whole paper. Sometimes, I do not know why, while writing with the digital pen, some parts of the letters are not displayed on the screen. For example, when writing the letter " $m$ ", the tail of the letter is not 
displayed. Or, when writing the word "log", it writes all the letters but L. I think this situation results from writing fast. And, when my hand covers the device, it sometimes does not sense everything. You have to rewrite them." [K2]

When the two instructors were asked if they received any assistance during the use of digital pen, they stated that they installed digital ink device with one of the research assistants before the course.

\section{Effects of the Use of Digital Pen on Instructors' Pedagogical Approaches (Teaching Method, Classroom and Time Management)}

When the participants were asked "Do you consider digital pen while planning your course?" K1 stated that he taught his first distance course with the help of a PowerPoint presentation and that students had some problems with it; that student comprehension, interest and participation increased after starting to use digital pen; and that, therefore, he considered digital ink when planning his course.

"...I started to use digital pen when teaching my course. Approximately 10-15 students participated in my first course. But now I have 30-35 students. Student reactions make me think that their interest and comprehension increased after I started to use digital pen. For this reason, I consider using a digital pen when planning my course."[K1]

$\mathrm{K} 2$ made the following statement for the same question:

"Digital pen did not add anything to the course planning. In fact, the digital pen only provided me with the flexibility that I already have in a traditional classroom environment."[K2]

The participants were asked if the use of digital pen had any effects on the teaching methods they used in the distance math course. K1 stated that this technology did not make a huge difference (compared to the traditional education environment) in the teaching method he used in the online learning environment. $\mathrm{K} 2$ commented that this was his first distance education experience and he had to prepare himself for the new system; however, he could not completely detach himself from the traditional method. Stating that digital pen enabled him to act similarly in traditional as well as online learning environments, K2 expressed, "...it enabled me to behave as I do in the traditional classroom environment."

When participants were asked if they could achieve the same quality level when teaching their course without using digital pen in distance education, K1 explained that it would be quite difficult to achieve the same quality level without using digital pen and that student interest, motivation and achievement would decrease in such a situation. He comments: "It is necessary to use [a] digital pen during the course. I think [a] digital pen is a prerequisite of distance education." K2 also expressed that it would be impossible to achieve the same quality level without using a digital pen in distance education.

In response to the question "Does the use of digital pen affect your classroom and time management?", K1 replied that digital pen increased participation but required more time than using PowerPoint. K2 explained that it would not be possible to teach the course via 
PowerPoint, that he had no problem with the classroom control and that he could not ensure students participation without using a digital pen. In terms of time management, K2 emphasized that digital pen saved time because "...students do not need to write anything and take additional notes". He also added that he could solve a greater number of questions in the online learning environment than in the traditional education environment.

After being asked "Do you think there are differences between online mathematics course taught with and without digital pen?" K1 addressed the issue from a student perspective and commented that student achievement would be lower:

"...you can teach history; however, you cannot teach a science course in online learning environment without digital pen. If you do so, students will not be interested in the course and lose their concentration at any point." [K1]

K2 explained that he would have some problems as follows:

"... without [a] digital pen, I would have to talk during the whole lesson. I could not write the mathematical symbols. Moreover, it would be difficult to plan the course, since it is quite complex and takes too much time to prepare a file using mathematical symbols in the Word format." [K2]

\section{Connection between the Use of Digital Pen and Student-Instructor Interaction}

When they were asked "Does the use of digital pen affect your interaction with your students?", the participants explained that interaction increased but there were some limitations in terms of student interaction despite the use of digital pen. The limitations stressed by both participants are summarized as: "their inability to see the computer screen (the online learning environment) when writing with a digital pen. Therefore, they cannot follow the messages written by the students, and students cannot interact in the course." K2 made the following statement on this issue: "... when I am writing something, a student asks a question. But since I cannot see the question, I continue writing."

Regarding whether instructors reorganize questions by considering the ability of students to answer them, it was found that they did not do it; however, they tended to prepare questions requiring shorter answers, because the students could answer using a small message box. On this issue, K1 said, "I can ask questions which can be answered in a few seconds" and K2 said "...I do not specifically change the question. I just ask for shorter answers."

Regarding the methods they adopted to overcome the difficulties experienced by the students when solving mathematical problems and how they understood the process steps at which students made mistakes, instructors stated that they could not understand at which process level students had difficulty. In order to eliminate this problem, K2 allowed students to speak and, following their comments, he resolved the problem.

\section{Advantages Offered to Instructors by the Use of Digital Pen}

When the participants were asked for their opinions about the beneficial aspects of the digital pen technology, two main benefits were that it provides the comfort of the traditional 
classroom environment and it enables the use of a board while lecturing in online learning environment. In relation to this issue, $\mathrm{K} 2$ commented:

"The digital pen helped me in approaching the online learning environment in a way similar to the traditional classroom environment with which I am familiar. I have to say that digital pen enabled me to feel relaxed and comfortable as I feel in the traditional classroom environment. I feel more comfortable in the online learning environment because of the digital pen."[K2]

In addition, the participants described a change in their attitudes towards online learning.

"...My colleagues mentioned such a system. I also knew about the system but I was afraid to use it since I had never used it before. I thought that the implementation would be hard and I also had a negative attitude towards distance education. After using digital pen, I gave my PowerPoint presentations and pdf files to students for their use. I started to use only the digital pen while lecturing." [K1]

"I had a negative attitude towards online learning. I thought math could not be learned through distance education. These applications, I mean applications with the digital pen, slowly changed my attitude." [K2]

\section{Instructors' Evaluation of the Use of Digital Pen from Student Perspective}

K1 stated that the use of a digital pen in the online learning environment increased student interest and participation in the course, and the students confirmed this.

"...I started to lecture with a digital pen. Students became more interested in the course. Approximately, 10-15 people had participated in my first course. Today, I have 30-35 students. Feedback makes me to think that student interest and comprehension increased after I started to use the digital pen." [K1]

"...Most of the students say that they enjoy following the course. Why? I lecture by writing down the subject as if students saw the subject for the first time." [K1]

K2 said that students can see the board in the online learning environment, as is the case in traditional education, and that students were satisfied with this opportunity:

"...math requires performing each process. In other words, students have to see you when performing process steps on the board... I can do this with the digital pen. And the students go through a more efficient and effective learning process. Students like the digital pen and they even want to use it themselves." [K2]

\section{Instructors' Suggestions about Online Courses}

The last theme defined was "instructors' suggestions about the online courses". The most important of these recommendations is that digital pen should be used by students as well as instructors. According to the participants, the use of digital pen by students will enable the instructor to see the process steps that the student follows and make the online learning 
environment more interactive. $\mathrm{K} 2$ answered the question of "What would be the situation if all students were provided a digital pen?" with the statement "It would be an interactive classroom, in other words, there would be more interaction." The other participant statements were as follows:

"...I want to see the process steps. Such a system would be beneficial. Let's assume that I ask a question, and then the student answers it using his/her digital pen and sends his/her answer to me. I will store these answers and evaluate as an exam paper." [K1]

Another method suggested by the participants to see student solutions is for the students to scan their solutions and share them in the online learning environment. However, both participants stated that this would take a long time and would be hard to implement.

\section{Study Observations}

Observations showed that both the participants had some problems during the use of digital pen. They contacted officers of the related distance education center and succeeded in solving these problems. They tried to solve the problems they encountered during the lectures by themselves and were generally successful. During the first three weeks of the courses, the participants had considerably fewer problems with using digital pen. As he specialized in technology, K2 adapted to digital pen quicker than K1 and had fewer problems. In addition, K2 preferred to solve the problems himself and was successful in doing so.

Both participants were observed spending a long time replacing the paper, not writing straight at times, and erasing incorrect statements. The following figures (Figure 1 and Figure 2) were collected from the online learning environment of $\mathrm{K} 1$ and $\mathrm{K} 2$, respectively.

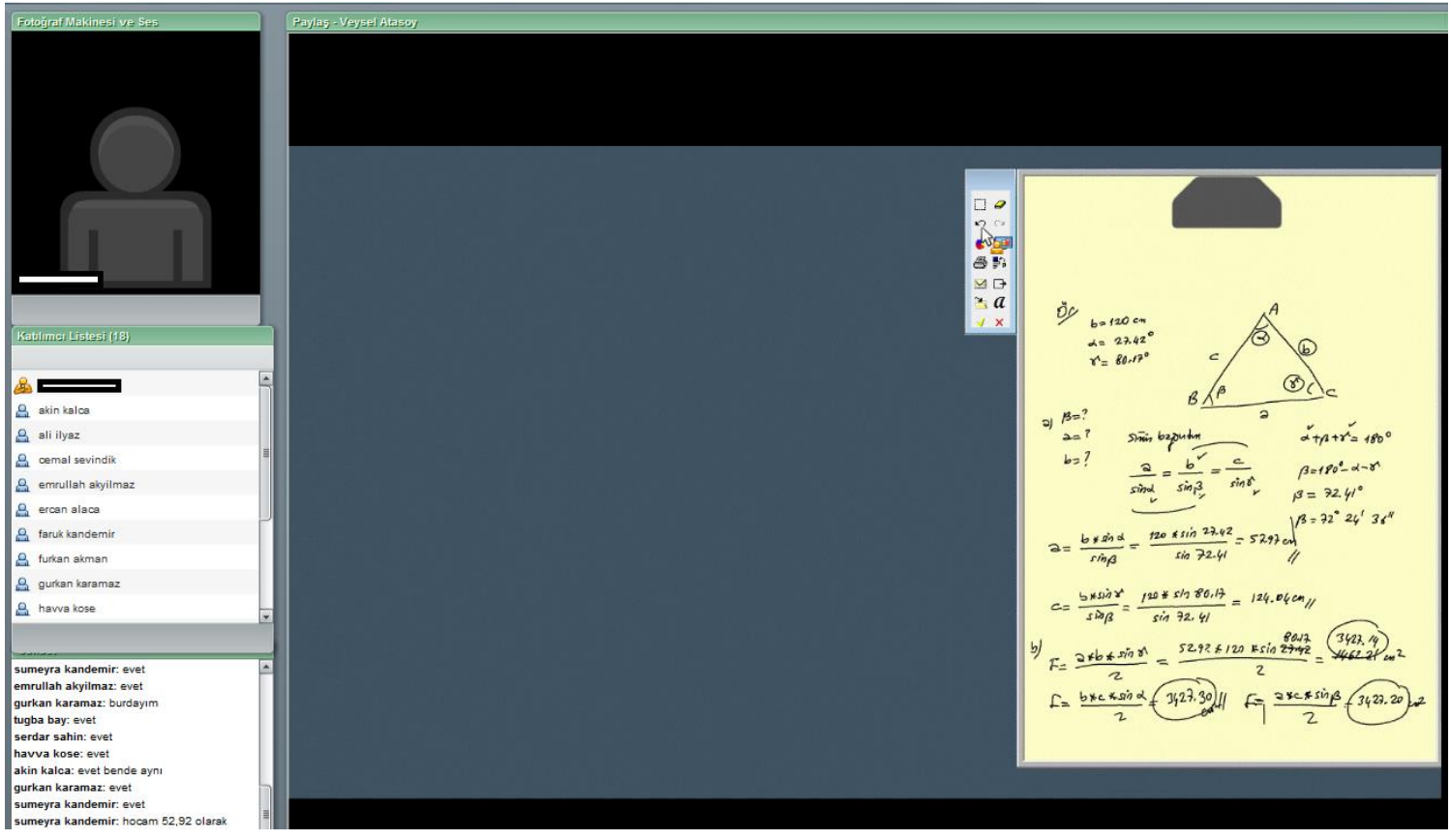

Figure 1.Screen Display from the Course Taught by K1 


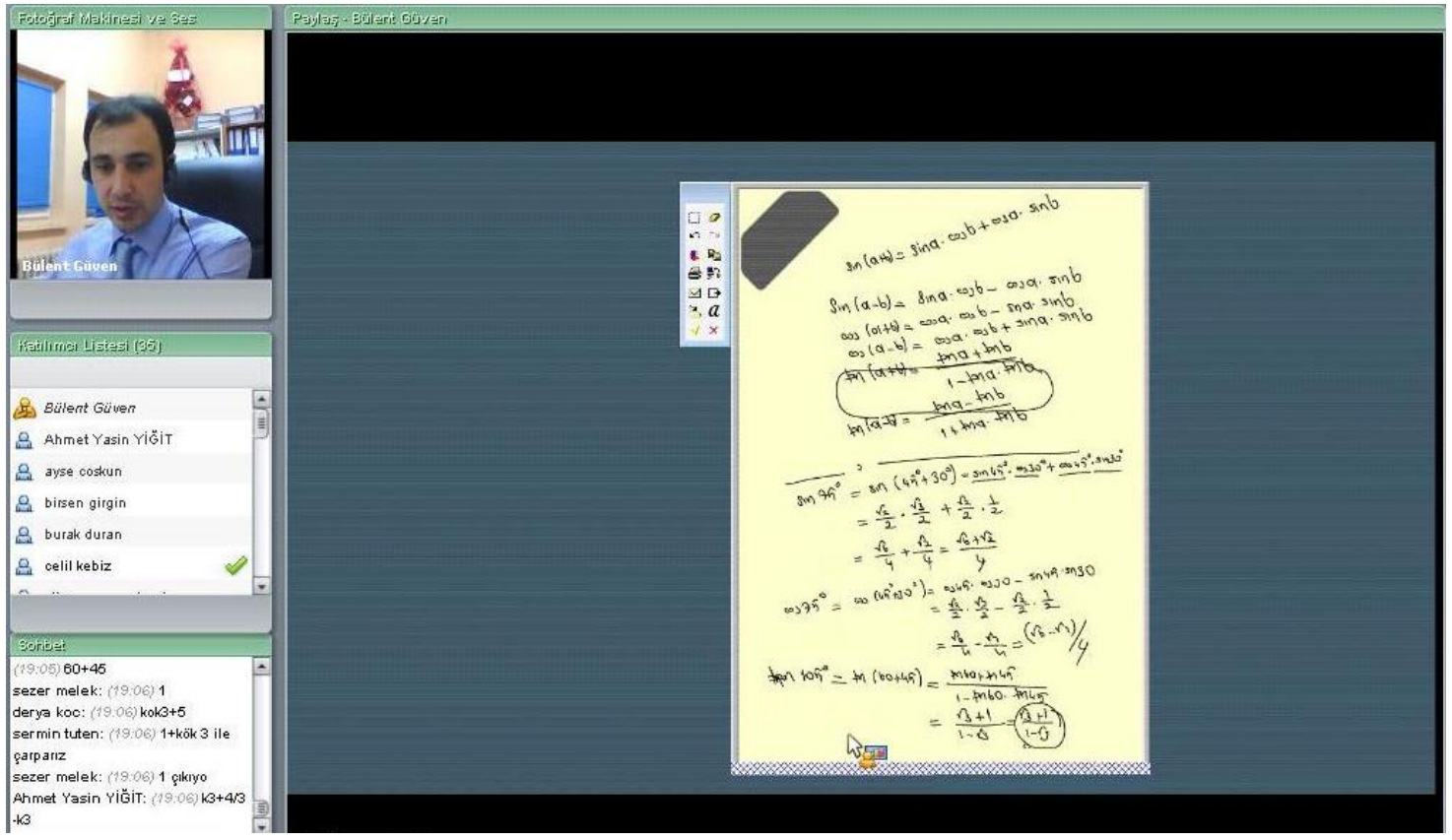

Figure 2. Screen Display from the Course Taught by K2

During the observations, student answers delivered through the message box in the online learning environment were analyzed carefully. Students were observed entering their answers into the message box via the keyboard and were seen not to have written many mathematical symbols except for $(+, /,-)$. The participants were recorded as taking this into consideration and asking questions requiring short answers.

Observations showed that participants tended to integrate traditional classroom practices into the online learning environment. The participants who were teaching for the first time in the online learning environment were confused about achieving time and classroom management and implementing teaching methods. They were observed to face problems, particularly in the display of mathematical symbols and the teaching of concepts; however, they were able to eliminate these problems with the help of digital pen. The participants were seen to change the pedagogical approaches they had adopted for the face-to-face learning environment by taking into consideration the unique opportunities of the online learning environment, and they adapted to the new environment.

\section{Discussion}

The participants stated that they did not have detailed information on the digital pen technology they used. Therefore, they suffered from some problems during the online mathematics course. One of the barriers for using digital technologies in the higher education classroom is instructor's lack of knowledge/skill about technology (Marzilli et al., 2014). Shaqour (2005) emphasized the necessity of instructors knowing how to use new educational technologies in order to provide efficient instruction with the help of the technologies introduced into the educational field. Developing the skills required for the use of digital technologies which play important roles in education brings instructors' professional success (Erdemir, Bakirci, \& Eyduran, 2009). 
The instructors who frequently use the board when teaching a mathematics course in the faceto-face learning environment stated that the use of digital pen in the online learning environment may replace board and chalk, thus providing the familiarity of the traditional education environment. They particularly emphasized the importance of the use of digital pen in the online mathematics course. In addition, they commented that online mathematics courses taught without digital pen might decrease student participation, and the quality of the course and prevent students from seeing the process steps of the problem solving. Galligan et al. (2010) stated the necessity of math teachers writing all process steps on the board to enable students to see the solutions. In addition, it was emphasized in the same study that no change could be made in teaching materials prepared in advance, such as PowerPoint presentations, used in both traditional and online learning environments during the course; that the use of technologies such as tablet computers and digital pens enabled teachers to have face to face contact the students; and that such technologies enabled the teachers to immediately answer student questions. The findings of this study support the results of the study by Galligan et al. (2010). Many studies indicate that it is hard and time consuming to express mathematical expressions like symbols and formulas via text and not experienced these challenges using technologies which has handwriting features such as digital pen and interactive whiteboards in online mathematics teaching (Alvarez et al., 2013; Hofacker \& Ernie, 2009; Hrastinski et al., 2014; McLaren, 2014; Mehlhorn et al., 2011; Oviatt et al., 2007).

Observations of the online learning environments made by the researchers in this study showed that the use of digital pen by the instructors only and focusing of the instructors on the paper when writing brought about some problems in terms of teacher-student interaction. The instructors stated that the use of digital pen by the students may increase the level of interaction and be beneficial for students in the online learning environment. The review of related studies in the literature shows that such technologies and the software compatible with these technologies are actively used by students and that the use of such technologies by students is quite effective in improving communication and interaction with teachers and other students (Galligan et al., 2010; Reins, 2007; Varadarajan et al., 2008; Wang, Gould, \& Fulton, 2007). In the study by Wang, Gould, and Fulton (2007), students stated that they found these technologies useful and that they provided a highly interactive learning environment which offered individualized learning opportunity. Students explained that in particular, penbased technologies enabled them to write their notes on the appropriate areas of any graphic provided by the teacher. These results support the opinions of the participants of the current study about the use of digital pen by students.

Participants stressed the high level of participation and high teacher-student interaction achieved in mathematics courses taught in the online learning environment. The results from the observations made by the researchers in this study support the responses of the participants to the interview questions. Similarly, Tutty and White (2006) stated that tablet computers and related technologies can also increase teacher-student interaction in the traditional learning environment. In addition, the findings of the current study support the results found by Wang, Fould, and Fulton (2007).

The participants of the present study highlighted the fact that their negative attitudes towards mathematics courses taught in an on line learning environment changed after using digital pen, and this made them feel as comfortable as they did in the traditional learning environment. Adnan and Boz (2015) indicated that faculty who have experience about online learning developed more positive opinions for the use of online technologies in math teaching. The instructors also stated that students enjoyed participating in the distance mathematics course 
taught via digital pen and that the use of digital pen increased student participation. These findings are parallel with the findings of the study by Galligan et al. (2010).

\section{Conclusions and Recommendations}

This study revealed instructors' experiences and perspectives about the effects of digital pen technology, a pen-based technology, in the mathematics course taught in an online learning environment. The results concluded via interpretation of the findings obtained in the study are as follows:

- Users should know how to use digital pen technology in online mathematics courses and how to overcome problems related to this technology. For this reason, instructors or faculty who are teaching mathematics online should know what technologies such as digital pen and interactive whiteboards are and how these technologies are used effectively in their courses. Also, when they encounter technical problems, they should know solutions about them. In this respect, support team of distance education centers can arrange in-service training for the teaching staff to teach how they use technology effectively in their online courses and gain some experiences in this regard.

- The use of digital pen technology in online mathematics course can increase communication and interaction in the learning environment. For this reason, using technologies like digital pen by students and instructors may increase participation in online courses.

- Teaching an online mathematics course without using digital ink technology may result in certain limitations in interactive and pedagogic terms. In particular, taking advantage of using technologies like digital pen in explaining the course content makes course design and management easier.

- In online mathematics course, it is necessary to use digital ink technology and related technologies in order to display concepts, symbols, and solution process steps, provide sufficient feedback, achieve a high level of interaction, and teach the course more efficiently.

- The instructors' bias against online mathematics courses was overcome with digital pen technology in this study, and this technology allowed instructors to feel more comfortable in the online learning environment. In this respect, best practices and effective solutions of using pen-based technologies in on line courses can be shown to inexperienced instructors with online mathematics courses before starting courses.

In line of the findings, it can be suggested that online students should also use digital ink technology in the online mathematics course just like online instructors. This suggestion may enable the maximization of teacher-student interaction, eliminate the feeling of isolation in an online learning environment and facilitate the display of the solving process steps of the math questions in a digital environment. In addition, compatible software should be developed to enable instructor access to students' works and the notes taken by the students on a specific platform. In this way, classroom control can be maintained more easily and instructors can provide instant feedback to students according to their applications and answers. 
This study highlights the fact that digital pen as a human-computer interaction technology may be helpful in establishing a highly-interactive learning environment and overcoming the limitations and barriers of the online learning environment in relation to online mathematics courses. Digital pen technology and similar technologies are concluded to be an indispensable element of the more efficient and higher-quality online courses.

\section{References}

Adnan, M. \& Boz, B. (2015). Faculty members' perspectives on teaching mathematics online: Does prior online learning experience count? Turkish Online Journal of Qualitative Inquiry, 6(1), 21-38.

Alvarez, C. Brown, C., \& Nussbaum, M. (2011). Comparative study of netbooks and tablet PCs for fostering face-to-face collaborative learning. Computers in Human Behavior, 27(2), 834-844.

Alvarez, C., Salavati, S., Nussbaum, M., \& Milrad, M. (2013). Collboard: Fostering new media literacies in the classroom through collaborative problem solving supported by digital pens and interactive whiteboards. Computers \& Education, 63, 368-379.

Anderson, T. (2003). Getting the mix right again: An updated and theoretical rationale for interaction. International Review of Research in Open and Distance Learning, 4(2), 9-14.

Artemeva, N. \& Fox, J. (2011). The writing's on the board: The global and the local in teaching undergraduate mathematics through chalk talk. Written Communication, 28, 345-379. doi:10.1177/0741088311419630

Baki, A. (2006). Kuramdan uygulamaya matematik eğitimi (3rd ed.). Trabzon: Derya.

Beaudoin, M. (2002). Learning or lurking? Tracking the 'invisible' online student. The Internet and Higher Education, 5(2), 147-155.

Beldarrain, Y. (2006). Distance Education Trends: Integrating new technologies to foster student interaction and collaboration. Distance Education, 27(2), 139-153.

Berge, Z. (2002). Active, interactive and reflective e-learning. Quarterly Review of Distance Education, 3(2), 181-190.

Bernhardt, W., Kress, M., Lewental, M., \& Miller, P. (2004, June). Digital ink for online teaching. Association of Small Computer Users in Education (ASCUE). Retrieved on 26 November 2014 from http://files.eric.ed.gov/fulltext/ED490096.pdf

Collis, B., De Boer, W., \& Slotman, K. (2001). Feedback for web-based assignments. Journal of Computer Assisted Learning, 17, 3, 306-313.

Denzin, N. K. \& Lincoln, Y. S. (2000). Introduction: The discipline and practice of qualitative research. In N.K. Denzin \& Y.S. Lincoln (eds.), Handbook of qualitative research, 1-29. Thousand Oaks, CA: Sage.

Dzakira, H. \& Idrus, R. M. (2003). Teacher-learner interactions in distance education: A case of two Malaysian universities. Turkish Online Journal of Distance Education, 4(3), 1-13.

Erdemir, N., Bakirci, H., \& Eyduran, E. (2009). Öğretmen adaylarının eğitimde teknolojiyi kullanabilme özgüvenlerinin tespiti. Journal of Turkish Science Education, 6(3), 99-108. 
Galligan, L., Loch, B., McDonald, C., \& Taylor, J. A. (2010).The use of tablet and related technologies in math teaching. Australian Senior Mathematics Journal, 24(1), 38-51.

Glass, J. \& Sue, V. (2008). Student preferences, satisfaction, and perceived learning in an online mathematics class. MERLOT Journal of Online Learning and Teaching, 4(3), 325-338.

Heddens, J. W. \& Speer, R.W. (1997).Today's mathematics (9th ed.). Upper Saddle River, NJ: Merrill an Imprint of Prentice-Hall.

Hofacker, E. \& Ernie, K. (2009). Using digital ink and podcasts to teach mathematics. In Proceedings from 21st Annual International Conference on Technology in Collegiate Mathematics. New Orleans, LA.

Hrastinski, S., Edman, A., Andersson, F., Kawnine, T., \& Soames, C. a., (2014) Informal math coaching by instant messaging: Two case studies of how university students coach K-12 students, Interactive Learning Environments, 22(1), 84-96.

Jin, S. H. (2005). Analyzing student-student and student-instructor interaction through multiple communication tools in web-based learning. International Journal of Instructional Media, 32(1), 59.

Johnson, R. \& Christensen, L. (2004).Educational research: Quantitative, qualitative and mixed approaches (2nd ed). Boston, MA: Allyn \&Bacon.

Jung, I., Choi, S., Lim, C., \& Leem, J. (2002). Effects of different types of interaction on learning achievement, satisfaction and participation in web-based instruction. Innovations in Education and Teaching International, 39(2), 153-62.

Karal, H., Kokoc, M., Colak, C., \& Yalcin, Y. (2013). Using pen-based technology in online mathematics course: An evaluation study. European Journal of Open, Distance and eLearning, 16(2), 152.

Liao, L. (2006). A flow theory perspective on learner motivation and behavior in distance education. Distance Education, 27(1), 45-62.

Lincoln, Y. S. \& Guba, E. G. (1985). Naturalistic inquiry. Beverly Hills, CA: Sage.

Maclaren, P. (2014). The new chalkboard: the role of digital pen technologies in tertiary mathematics teaching. Teaching Mathematics and Its Applications, 33(1), 16-26.

Marzilli, C., Delello, J., Marmion, S., McWhorter, R., Roberts, P., \& Marzilli, T. S. (2014). Faculty attitudes towards integrating technology and innovation. International Journal on Integrating Technology in Education, 3(1), 1-20.

McMillan, J. H. (2000). Educational research: Fundamentals for the consumer (4th ed.). New York: Longman.

McMillan, J. H. \& Schumacher, S. (2010). Research in education: Evidence-based inquiry (7th ed.). London: Pearson.

Mehlhorn, S., Parrott S., Mehlhorn, J., Burcham, T., Roberts, J., \& Smartt, P. (2011, February).Using digital learning objects to improve student problem solving skills. Paper presented at the meeting of the Southern Agricultural Economics Association Annual Meeting, Corpus Christi, Texas. Retrieved on 26 November 2014 from http://ageconsearch.umn.edu/bitstream/98763/2/LivescribeSAEAPaperFINAL.pdf

Miles, M. B. \& Huberman, M. A. (1994).Qualitative data analysis: An expanded sourcebook (2nd ed.). Beverley Hills, CA: Sage. 
Moore, S. (1997). The role of the teacher in distance education: The teacher perspective. Paper presented at the Sixth Annual International Conference for Community \& Technical College Chairs, Deans, and Other Organizational Leaders. Reno, Nevada.

Moreno-Ger, P., Burgos, D., Martínez-Ortiz, I., Sierra, J.L., \& Fernández-Manjón, B. (2008). Educational game design for online education. Computers in Human Behavior, 24(6), 2530-2540.

Morewood, A. L., Ankrum, J. W., \& Bean, R. M. (2010).Teachers' perceptions of the influence of professional development on their knowledge of content, pedagogy, and curriculum. College Reading Association Yearbook, 31, 201-219.

Morse, J. M. (1991). Strategies for sampling. In J. Morse (Ed.), Qualitative nursing research: $A$ contemporary dialogue (pp. 127-145). Newbury Park, CA: Sage.

Nehme, Z. (2008). The social arena of the online synchronous environment. Turkish Online Journal of Distance Education, 9(2), 238-243.

Newby, T. J., Stepich, D. A., Lehman, J. D., \& Russell, J. D. (2006). Educational technology for teaching and learning. Upper Saddle River, NJ: Pearson Merrill/Prentice Hall.

Offir, B., Lev, Y., \& Bezalel, R. (2008). Surface and deep learning processes in distance education: Synchronous versus asynchronous systems. Computers \& Education, 51(3), 1172-1183.

Oviatt, S., Arthur, A., Brock, Y., \& Cohen, J. (2007, July). Expressive pen-based interfaces for math education. Proceedings of the 8th International Conference on Computer Supported Collaborative Learning (pp. 573-582). International Society of the Learning Sciences.

Patton, M. (2002).Qualitative research and evaluation methods (3rd ed.). Thousand Oaks, CA: Sage.

Reins, K. (2007). Digital tablet pcs as new technologies of writing and learning: A survey of perceptions of digital ink technology. Contemporary Issues in Technology and Teacher Education, 7(3), 158-177.

Roblyer, M. D. (2006). Integrating educational technology into teaching (4th ed.) Upper Saddle River, NJ: Merrill/Prentice Hall.

Schunk, D. H. (2008). Learning theories: An educational perspective (5th ed.). Upper Saddle River, NJ: Merrill Prentice Hall.

Shaqour, A. Z. H. (2005). A model for integrating new technologies into pre-service teacher training programs Ajman University (A case study).The Turkish Online Journal of Educational Technology, 4(2), 1, 3-6.

Siozos, P., Palaigeorgiou, G., Triantafyllakos, G., \& Despotakis, T. (2009). Computer based testing using "digital ink": Participatory design of a tablet PC based assessment application for secondary education. Computers \& Education, 52(4), 811-819.

Sowell, E. J. (2001). Educational research: An integrative introduction. Boston: McGraw-Hill Higher Education.

Temizoz, Y. \& Ozgun-Koca, S. A. (2008).The instructional methods that mathematics teachers use and their perceptions on the discovery approach. Education and Science, 33(149), 89-103. 
Thurmond, V. \& Wambach, K. (2004). Understanding interactions in distance education: A review of the literature. International Journal of Instructional Technology and Distance Learning, 1(1), 9-26

Tutty, J. \& White, B. (2006). Tablet classroom interactions. Australian Computer Science Communications, 28(5), 229-235.

Varadarajan, A., Pately, N., Maxim, B., \& Grosky, W.I. (2008).Analyzing the efficacy of using digital ink devices in a learning environment. Multimedia Tools and Applications, 40(2), 211-239.

Wang, H., Gould, L., \& Fulton, D. (2007). Bridge the virtual gap: Using new technology to enhance interaction in distance learning. International Journal of Instructional Technology and Distance Learning, 4(3), 67-70.

Watson, S. (2010). Increasing online interaction in a distance education MBA: Exploring students' attitudes towards change. Australasian Journal of Educational Technology, 26(1), 63-84.

Wellington, J. (2000). Educational research, contemporary issues and practical approaches. London: Continuum.

Yildirim, A. \& Simsek, H. (2008). Nitel arastirma yontemleri ( $7^{\text {th }}$ ed.). Ankara: Seckin.

Yin, R. K. (1994). Case study research: Design and methods ( $2^{\text {nd }}$ ed.). Beverly Hills, CA: Sage.

Correspondence: Hasan Karal, Associate Professor, Department of Computer Education and Instructional Technologies, Fatih Faculty of Education, Karadeniz Technical University, Trabzon, Turkey 